\title{
Medical interns' knowledge of tuberculosis and DOTS strategy in northern Islamic Republic of Iran
}

\author{
A.R. Charkazi, ${ }^{1}$ G. Kouchaki, ${ }^{2}$ M. Soleymani Nejad ${ }^{7}$ and A.H. Gholizade ${ }^{3}$
}

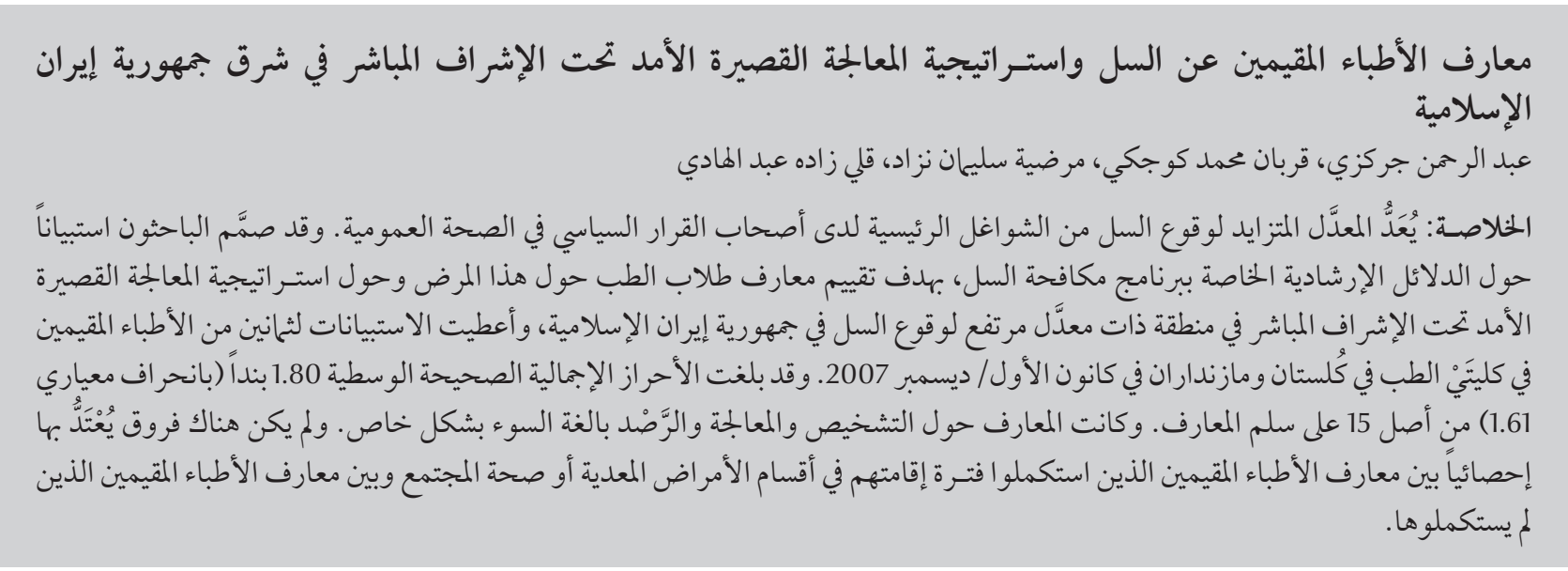

ABSTRACT The increasing incidence of tuberculosis (TB) is a major concern to public health policy-makers. To assess knowledge about TB and the DOTS strategy among medical students in a high incidence area of the Islamic Republic of Iran, a questionnaire designed around the national TB programme guidelines was given to 80 interns in Golestan and Mazandaran medical schools in December 2007. The overall mean knowledge score was 1.80 (SD 1.61) items correct out of 15. Knowledge about diagnosis, treatment and monitoring was especially poor. There were no significant differences between the knowledge of interns who had completed their internships in the infectious diseases or community health departments compared with those who had not.

Connaissances des internes en médecine sur la tuberculose et sur la stratégie du traitement de durée brève sous surveillance directe dans la partie septentrionale de la République islamique d'Iran

RÉSUMÉ L'incidence croissante de la tuberculose est une préoccupation majeure pour les responsables politiques de la santé publique. Pour évaluer les connaissances des étudiants en médecine sur la tuberculose et sur la stratégie du traitement de durée brève sous surveillance directe dans une zone d'incidence élevée de la République islamique d'Iran, un questionnaire élaboré à partir des directives nationales du programme de lutte contre la tuberculose a été administré à 80 internes des facultés de médecine de Golestan et Mazandaran, en décembre 2007. Le score moyen global était d'1,80 réponse exacte (E.T. 1,61) sur un total de 15 questions. Les connaissances concernant le diagnostic, le traitement et le suivi étaient particulièrement insuffisantes. II n'y avait pas de différences significatives entre les connaissances des internes qui avaient effectué leur internat dans le service des maladies infectieuses ou dans les services de santé communautaires et les connaissances des internes d'autres services. 


\section{Introduction}

The increasing incidence of tuberculosis (TB) is a major concern to public health policy-makers in both developing and developed countries [1-3]. Approximately one-third of the world's population is infected with Mycobacterium tuberculosis, and 3 million people die every year due to TB [4]. Today, in spite of $M$. tuberculosis screening, vaccines and effective anti-TB drugs, it is still a major global public health problem $[5,6]$. Incorrect and insufficient treatment, the emergence of multi-drug resistant (MDRTB) strains and the co-epidemic with HIV all contributed to the failure of TB control, prompting the World Health Organization (WHO) to pronounce TB a global emergency in 1993 [1].

In the Islamic Republic of Iran the incidence of TB decreased steadily from 34 per 100000 population in 1993 to 13.2 per 100000 population in 2006, after the introduction of the WHO recommended TB control strategy known as directly-observed treatment short-course (DOTS). In several regions such as Sistan va Baluchistan and Golestan provinces the incidence of TB is higher than in other regions [7]. Medical interns, as future specialist and general physicians (GPs), are the backbone of any health care system and are in a position to make an impact on TB control. Nevertheless, there is limited data about knowledge of TB and the DOTS strategy among medical interns. Previous studies conducted in the Islamic Republic of Iran showed poor knowledge about TB and DOTS among GPs in the public and private health sectors [8-10].

In view of the importance of physicians' collaboration in TB care to achieve control of the disease, we designed this study to evaluate knowledge of TB control and its management via the DOTS strategy among the medical interns of Golestan and Mazandaran medical schools in the northern part of the Islamic Republic of Iran.

\section{Methods}

A cross-sectional study was carried out in December 2007, simultaneously among interns of Golestan University of Medical Sciences in Gorgan city and Mazandaran University of Medical Sciences in Sari city.

\section{Participants}

To recruit participants for the study, a list of all interns resident in 7 hospitals (4 in Sari and 3 in Gorgan) were obtained from the medical schools. All departments and wards in the hospitals were visited to recruit the students to the study. Of the 103 eligible students 23 dropped out (15 in Gorgan and 8 in Sari), giving a final sample of 80 students. Interns gave verbal consent to participate after being given assurances of confidentiality and anonymity. A repeat visit was conducted on the subsequent 3 days to include interns who were absent during the first visit or could not be contacted as they were off-duty or busy at the time.

\section{Data collection}

Data were gathered using a selfadministered questionnaire with a mix of open- and closed-ended questions. The first section recorded some background information (age, sex, university and whether they had completed internships in departments where the subject of TB is taught routinely). The second section assessed TB knowledge based on the DOTS strategy including: meaning of the acronym DOTS, description of the DOTS concept, meaning of the term MDR-TB, usual mode of transmission of TB, most common symptoms of pulmonary $\mathrm{TB}$, the best tests for diagnosis of pulmonary $\mathrm{TB}$ and for monitoring of treatment, categories of TB treatment, the recommended anti-TB regimen in the initial and continuous phases, definition of failure of TB treatment, criterion for a cured person and the types of TB that need long-term treatment.
The questionnaire was designed using the national tuberculosis programme guidelines and its validity was determined by assessing its content validity and testing its reliability by testretest $(r=0.85)$.

\section{Statistics}

All data were entered into SPSS, version 13 for Windows, and double entry of data was used in order to check for data entry accuracy. Independent $t$-tests were performed to analyse any differences in mean knowledge. Values of $P \leq 0.05$ were considered significant. All other measures were subject to descriptive statistics. Interns' knowledge level was described as high if they scored $>75 \%$ correct answers, moderate if 50\%-75\% correct or low if $<50 \%$ correct.

\section{Results}

\section{Background data of participants}

The participants comprised 44 (55\%) men and 36 (45\%) women. Their mean [standard deviation (SD)] age was 25.8 (SD 1.5) years, range 24-31 years. Of these, $28.8 \%$ had completed their internship in the infectious diseases ward and $27.5 \%$ in the community health department. The participants' demographic characteristics are shown in Table 1.

\section{DOTS strategy and MDR-TB}

Over $90 \%$ of the participants were unable to define the DOTS acronym and $83.8 \%$ could not describe the DOTS concept; $57.5 \%$ were unable to define the term MDR-TB (Table 2).

\section{Transmission and symptoms}

A majority of interns (85.0\%) correctly identified TB as a droplet infection, while some thought that sexual intercourse (8.7\%) and digestion (5.0\%) were routes of transmission (Table 3).

Two-fifths (40.0\%) mentioned coughing for 3 weeks or more as an important symptom of pulmonary 


\begin{tabular}{|c|c|c|}
\hline Variable & No. & $\%$ \\
\hline \multicolumn{3}{|l|}{ Sex } \\
\hline Male & 44 & 55.0 \\
\hline Female & 36 & 45.0 \\
\hline \multicolumn{3}{|l|}{ Age (years) } \\
\hline $23-24$ & 15 & 18.8 \\
\hline $25-26$ & 44 & 55.0 \\
\hline $27-28$ & 16 & 20.0 \\
\hline $29-30$ & 4 & 5.0 \\
\hline $30+$ & 1 & 1.2 \\
\hline \multicolumn{3}{|l|}{ Medical school } \\
\hline Mazandaran, Sari & 52 & 65.0 \\
\hline Golestan, Gorgan & 28 & 35.0 \\
\hline \multicolumn{3}{|c|}{ Completed internship in: } \\
\hline Infectious diseases & 23 & 28.8 \\
\hline Community health & 22 & 27.5 \\
\hline
\end{tabular}

TB; other answers included chest pain (20.0\%), dyspnoea (15.0\%) and haemoptysis (12.5\%) (Table 3$)$.

\section{Diagnosis and follow-up}

Only $17.5 \%$ considered sputum smears for acid-fast bacilli (AFB) as the best test for diagnosis of pulmonary $\mathrm{TB}$, while 60.0\% proposed chest X-ray (Table 3 ). Only $6.3 \%$ considered sputum microscopy as the best test for follow-up of cases under treatment, while $85.0 \%$ thought it was chest X-ray.

\section{Treatment and management}

Only a few participants (7.5\%) were able to define categories of TB treatment and duration of consumption of drugs in 2 categories (Table 4). Fourfifths $(80.0 \%)$ were unable to recommended which anti-TB drugs should be used in each category. Asked to name the 4 types of TB that need long-term chemotherapy (miliary, CNS, meningeal and skeletal TB), 58.8\% could not identify even 1 type. Very few knew how to define TB treatment failure and only 2 respondents were able to give the definition of a cured case of TB.

\section{Knowledge assessment}

The overall mean knowledge score for the 80 interns was 1.80 (SD 1.61) correct answers from a maximum of 15 . Knowledge of all interns was poor: none of them achieved a moderate or high score. There was no significant difference between the knowledge of interns who had completed their internships in the infectious diseases or community health departments and those who had not (data not shown).

\section{Discussion}

In this study interns working in 7 medical centres in Gorgan and Sari had very weak knowledge of TB. Our results are consistent with the findings of studies in other regions and countries such as those of Shehzadi [11], Khan [12], Harries [13], Lotfi [8], Nojoomi [9] and Talaeei [10], in which most interns and GPs had insufficient knowledge. Our study also showed that poor knowledge of TB among interns was not affected by the type of ward they had worked in. Students who had completed their internships in the infectious diseases and community health departments, where the subject of TB is taught routinely, had no better knowledge than those who had no experience in these fields.

Our findings about knowledge of transmission of $M$. tuberculosis were con sistent with studies of medical students, residents and interns in Pakistan, the United States of America and Nigeria, although subjects there were somewhat better informed, with 96\%, 95\% and $88.1 \%$ knowing that droplet infection was the usual mode of transmission compared with $85.0 \%$ in our study $[12,14,15]$. A study among GPs in Pakistan showed that only $68 \%$ correctly identified TB as a droplet infection [11]. Two studies in India and the Philippines showed poor knowledge about the mode of transmission, with about $4 \%$ of interns and $21 \%$ of physicians aware that droplet infection was the only route of transmission $[16,17]$.

Cough for 3 weeks or more is considered to be the primary symptom of

\begin{tabular}{|c|c|c|c|c|c|c|}
\hline \multirow[t]{2}{*}{ Item } & \multicolumn{2}{|c|}{ Correct response } & \multicolumn{2}{|c|}{ Incorrect response } & \multicolumn{2}{|c|}{ No response } \\
\hline & No. & $\%$ & No. & $\%$ & No. & $\%$ \\
\hline Define the acronym for DOTS & 3 & 3.8 & 36 & 45.0 & 41 & 51.2 \\
\hline Describe the DOTS concept ${ }^{\mathrm{a}}$ & 13 & 16.2 & 67 & 83.8 & 0 & 0 \\
\hline Define the term MDR-TB ${ }^{b}$ & 34 & 42.5 & 46 & 57.5 & 0 & 0 \\
\hline
\end{tabular}

${ }^{a}$ Strategy to assure consumption of anti-TB drugs in the initial phase of pulmonary TB treatment when it is supported by health workers; ${ }^{b}$ TB that is resistant to at least isoniazid and rifampicin. 


\begin{tabular}{|c|c|c|}
\hline \multicolumn{3}{|c|}{$\begin{array}{l}\text { Table } 3 \text { Knowledge among interns about transmission, symptoms, diagnosis and } \\
\text { follow-up of tuberculosis (TB) }(\boldsymbol{n}=\mathbf{8 0})\end{array}$} \\
\hline Knowledge item for pulmonary TB & $\begin{array}{l}\text { No. correct } \\
\text { responses }\end{array}$ & $\%$ \\
\hline \multicolumn{3}{|l|}{ Usual mode of transmission } \\
\hline Droplet infection & 68 & 85.0 \\
\hline Sexual transmission & 4 & 5.0 \\
\hline Digestion & 3 & 3.8 \\
\hline No response & 5 & 6.2 \\
\hline \multicolumn{3}{|l|}{ Most common symptom } \\
\hline Coughing for 3 weeks & 32 & 40.0 \\
\hline Chest pain & 16 & 20.0 \\
\hline Dyspnoea & 12 & 15.0 \\
\hline Haemoptysis & 10 & 12.4 \\
\hline Fever & 7 & 8.8 \\
\hline Weight loss & 3 & 3.8 \\
\hline \multicolumn{3}{|l|}{ Best test for diagnosis } \\
\hline Chest X-ray & 48 & 60.0 \\
\hline Smear culture & 18 & 22.5 \\
\hline AFB sputum microscopy & 14 & 17.5 \\
\hline \multicolumn{3}{|l|}{ Treatment monitoring } \\
\hline Chest X-ray & 68 & 85.0 \\
\hline Smear culture & 7 & 8.7 \\
\hline AFB sputum microscopy & 5 & 6.3 \\
\hline
\end{tabular}

$A F B=$ acid-fast bacilli.

pulmonary $\mathrm{TB}$ according to $\mathrm{WHO}$ guidelines. Two-fifths of interns in our study were able to identify this symptom, although in a high prevalence region such as Golestan province this rate of knowledge was inadequate and should be higher. In contrast, in India, Pakistan, the Philippines and Somalia, physicians and medical interns were very knowledgeable about the presenting symptoms of pulmonary TB [16-19].

We found that few interns indicated sputum smear microscopy for diagnosis of TB or as a follow-up test. Sputum microscopy has a high specificity and low rate of false negatives. It is considered to be the most efficient method for diagnosis of pulmonary $\mathrm{TB}$, and is advocated under the DOTS strategy worldwide. Interns in Pakistan and India were somewhat better informed about sputum smear microscopy $[12,16]$. Studies performed in other parts of world showed students' and physicians' knowledge ranging from $38 \%$ to $85 \%$ [12,14,19-23].

The interns had poor knowledge regarding treatment monitoring: a mere $6.3 \%$ were aware of AFB sputum microscopy as a monitoring tool. Their counterparts in Pakistan were better informed with $43.5 \%$ aware [12]. A study in Ethiopia revealed similar levels of knowledge among physicians [24]. However, in a study of actual practices in Pakistan, no sputum smear tests were conducted during treatment [25].

A large proportion of our interns were unfamiliar with appropriate treatment regimens in the initial and continuation phases of the national tuberculosis control programme, which is based on $\mathrm{WHO}$ guidelines. Almost none of the respondents knew the meaning of the DOTS acronym. Their counterparts in Pakistan were slightly better informed with about $18 \%$ able to define it [12]. Similarly, most of the students in our study were unable to define the basic concept of the DOTS strategy. When asked to write the drugs and their duration used in the initial phase (2 months

\begin{tabular}{|c|c|c|c|c|c|c|}
\hline \multirow[t]{2}{*}{ Question } & \multicolumn{2}{|c|}{ Correct response } & \multicolumn{2}{|c|}{ Incorrect response } & \multicolumn{2}{|c|}{ No response } \\
\hline & No. & $\%$ & No. & $\%$ & No. & $\%$ \\
\hline Categories of TB treatment and duration of use of drugs & 6 & 7.5 & 56 & 70.0 & 18 & 22.5 \\
\hline Drugs and doses used in both initial and continuous phase & 16 & 20.0 & 52 & 65.0 & 12 & 15.0 \\
\hline Definition of failure of TB treatment & 11 & 13.7 & 21 & 26.3 & 48 & 60.0 \\
\hline Criteria for cured case & 2 & 2.5 & 12 & 15.0 & 66 & 82.5 \\
\hline \multicolumn{7}{|l|}{ Types of TB which need long-term chemotherapy $(n=79)$ : } \\
\hline 4 types & 1 & 1.3 & - & - & - & - \\
\hline 3 types & 1 & 1.3 & - & - & - & - \\
\hline 2 types & 7 & 8.8 & - & - & - & - \\
\hline 1 type & 23 & 28.8 & - & - & - & - \\
\hline None & 47 & 58.8 & - & - & - & - \\
\hline
\end{tabular}


of isoniazid/rifampicin/pyrazinamide/ ethambutol) and the continuous phase (4 months of isoniazid/rifampicin) of treatment, only $20 \%$ of the interns were correct. This lack of knowledge about correct prescribing may lead to the spread of MDR-TB strains. In 2 surveys conducted among interns in India and Pakistan, the rates of correct knowledge of the recommended regimen were $7.8 \%$ and $56.5 \%$ respectively $[12,16]$. Other studies conducted in various countries about the prescribing behaviour of GPs reported similar findings $[18,20,24,26,27]$.

The definition of treatment failure, i.e. if a patient is AFB-positive for 5 months or more after treatment begins, was correctly answered only by $13.8 \%$ of respondents. Treatment failure is a sign that the TB management and control programme is inadequate and is a risk for MDR-TB in the community.
Four types of TB need long-term treatment for 8 months: meningeal TB, miliary TB, CNS and skeletal TB. Only 1 of our participants knew all of these and 1 knew 3 types. Almost 60\% abstained from responding, showing poor knowledge about this aspect of TB.

Several limitations of this study restrict the generalizability of the findings. Only 2 medical schools out of the 44 in the Islamic Republic of Iran were surveyed, and information about those who did not wish to participate was not collected.

\section{Conclusions}

In conclusion, this study demonstrated poor of knowledge about TB according to the $\mathrm{WHO}$ and national tuberculosis programme guidelines among interns in Sari and Gorgan in 2007. We suggest that comprehensive, updated, in-service training is needed among undergraduates, with special emphasis on the DOTS strategy, and appropriate changes in the undergraduate medical teaching curriculum. Similar studies need to be conducted in other parts of country among interns, especially in regions with a high prevalence and incidence of TB such as Sistan va Baluchistan and southern Khorasan.

\section{Acknowledgements}

This work received financial support from Golestan Medical Sciences University. We are very grateful to all interns who participated in this study and took time out of their busy lives to complete the questionnaire. We are also very thankful to Razieh Parvar, Rahimeh Arazi, Mina Kalteh and Aeazam Masoudi.

\section{References}

1. Lee JW. Global health improvement and WHO: shaping the future, Lancet, 2003, 362:2083-2088.

2. World Health Report 2003. Shaping the future. Geneva, World Health Organization, 2003.

3. Global tuberculosis control: surveillance, planning, financing. WHO report 2004. Geneva, World Health Organization, 2004 (WHO/HTM/TB/2004.331).

4. Dolin PI, Raviglione MC, Kochi A. Global tuberculosis incidence and mortality during 1990-2000. Bulletin of World Health Organization, 1994, 72:213-220.

5. Global tuberculosis control: surveillance, planning, financing. WHO report 2005. Geneva, World Health Organization, 2005 (WHO/HTM/TB/2005.349).

6. Mir Haggani L, Nasehi M. [National guidelines for combating TB. Iranian Ministry of Health, 1st ed]. Tehran, Islamic Republic of Iran, Seda Publisher, 2002 [in Farsi].

7. [Prevalence and Incidence of TB in Iran. Annual report of Iranian Ministry of Health]. Tehran, Islamic Republic of Iran, Ministry of Health, 2006 [in Farsi].

8. Lotfi $\mathrm{H}$, Arabnejad B. [The survey of private general practitioners knowledge about pulmonary TB and DOTS strategy in Iran]. Tabibe-E-Shargh, Journal of Zahedan University of Medical Sciences and Health Services, 2004, 6:25-32 [in Farsi].

9. Nojoomi M, Mokhberol Safa L, Jamali A. [Study of knowledge and attitude of private general physicians of Karaj city regarding national TB programs]. Iranian Journal of Respiratory Disease, Thoracic Surgery, Intensive Care and Tuberculosis, 2003, 6(2):67-73 [in Farsi].

10. Tallaei H, Yadegari D, Shahid N. [The study of GPs knowledge from control and treatment of TB via DOTS strategy: its neces- sity to medical school curriculum]. Iranian Journal of Infectious Disease and Tropical Medicine, 2002, 18(7):72-78 [in Farsi].

11. Shehzadi $\mathrm{R}$ et al. Knowledge regarding management of tuberculosis among general practitioners in northern area of Pakistan. Pakistan Medical Association Journal, 2005, 55(4):74-76.

12. Khan JA et al. Medical interns knowledge of TB in Pakistan. Tropical Doctor, 2005, 35(3):44-47.

13. Harries AD et al. Teaching tuberculosis control to medical undergraduates: the Malawi experience. International Journal of Tuberculosis and Lung Disease, 2003, 7(9):842-847.

14. Karakousis P et al. U.S. medical resident familiarity with national tuberculosis guidelines. BMC Infectious Diseases, 2007, 7:89.

15. Bousari O, Adeyemi A, Bousari O. Knowledge of tuberculosis and its management practices among medical interns in a resource-poor setting: implications for disease control in subSaharan Africa. Internet Journal of Infectious Diseases, 2008, 6(2).

16. Rajpal S et al. Knowledge, attitude and practices regarding tuberculosis and DOTS among interns in Delhi, India. Journal of the College of Physicians and Surgeons of Pakistan, 2007, 17(8):457-461.

17. Yu CT et al. Pulmonary tuberculosis: knowledge, attitude and practices of selected physicians in tertiary-care hospital. Philippine Journal of Microbiology and Infectious Diseases, 2002, 31(1):1-8.

18. Khan J et al. Tuberculosis diagnosis and treatment practices of private physician in Karachi, Pakistan. Eastern Mediterranean Health Journal, 2003, 9:769-775. 
19. Suleiman BA et al. Do doctors in north western Somalia follow the national guidelines for tuberculosis management? Eastern Mediterranean Health Journal, 2003, 9:789-795.

20. Hong YP et al. Survey of knowledge, attitude and practices for tuberculosis among general practitioners. Tubercle and Lung Disease, 1995, 76:431-435.

21. Uplekar MW, Sheela R. Private doctors and tuberculosis control in India. Tubercle and Lung Disease, 1993, 74:332-337.

22. Uplekar MW et al. Tuberculosis management in private practice and its implications. Indian Journal of Tuberculosis, 1996, 43:19-22.

23. Uplekar MW et al. Tuberculosis patients and practitioners in private clinics in India. International Journal of Tuberculosis and Lung Disease, 1998, 2:324-329.
24. Shimeles E et al. Knowledge and practice of private practitioners in TB control in Addis Ababa. International Journal of Tuberculosis and Lung Disease, 2006, 10:1172-1177.

25. Arif $\mathrm{K}$ et al. Physician compliance with national tuberculosis treatment guidelines: a university hospital study. International Journal of Tuberculosis and Lung Disease, 1997, 2:225-230.

26. Hussain A et al. Adherence of private practitioners with the national tuberculosis treatment guidelines in Pakistan: a survey report. Journal of Pakistan Medical Association, 2005, 55:17-19.

27. Olle-Goig JE. A survey of prescribing patterns for tuberculosis treatment amongst Doctors in a Bolivian city. International Journal of Tuberculosis and Lung Disease, 1993, 3:74-78.

\section{Health promises and perils in an interdependent world: breaking the cycle of poverty, misery, and illness}

Extract from an address delivered at Tokyo Women's Medical University on 18 November 2010 by Dr Margaret Chan, DirectorGeneral of the World Health Organization

As we now know from decades of research and experience, the education of girls and women is indeed transformational. The financial independence of women is indeed closely linked to their social status. The social status of women is a major determinant of health for women, their families, and communities.

In sub-Saharan Africa, for example, ... the rural woman ... is often the breadwinner, the caregiver, and the beast of burden. She may spend as many as four hours every day fetching water and fuel. She is overworked, undereducated, and locked into poverty. Her life is one of hardship and drudgery, fraught with risks to health. She will have a number of children, closely spaced, rightly assuming that some will die because of malaria, measles, pneumonia, malnutrition, or the many other ills closely linked to poverty. Her risk of dying during pregnancy and childbirth is nearly four hundred times greater than it is here in Japan.

This is the starkest statistic in public health: the difference in maternal mortality in rich countries compared with poor countries, where more than $99 \%$ of these deaths occur.

As we know today, the number of maternal deaths will not go down until more women have skilled attendants at birth and access to emergency obstetric care. This is a health systems issue, a matter of capacity and infrastructure, involving the proximity and quality of health services, transportation, staff, skills, supplies, and, of course, an ability to pay. The full text of Dr Chan's address is available at: http://www.who.int/dg/speeches/2010/tokyo_20101118/en/ index.html 